\title{
SUCCESSFUL PREGNANCY OUTCOME IN SUB-MUCOUS MYOMA: A CASE REPORT
}

\author{
Susmita Bhattacharya ${ }^{1}$, Harish K. M², Nonibala Devi ${ }^{3}$, N. Nabakishore Singh ${ }^{4}$, L. Ranjit Singh ${ }^{5}$
}

\section{HOW TO CITE THIS ARTICLE:}

Susmita Bhattacharya, Harish K. M, Nonibala Devi, N. Nabakishore Singh, L. Ranjit Singh. "Successful Pregnancy Outcome in Sub-Mucous Myoma: A Case Report". Journal of Evolution of Medical and Dental Sciences 2014; Vol. 3, Issue 28, July 14; Page: 7692-7695, DOI: 10.14260/jemds/2014/2957

\begin{abstract}
Myomas are the most common benign tumors of the female genital tract and are associated with numerous clinical problems including a negative impact on fertility. Myomas that compress the uterine cavity like submucous myomas significantly reduce pregnancy rates. CASE: A 29 year old primi-gravida woman with term pregnancy (39 weeks 2days) came to the out-patient department, of the department of Obstetrics and Gynecology with pain abdomen on 26th July, 2013 and got admitted. On per vaginal examination cephalo- pelvic disproportion was detected and emergency lower segment caesarean section was done under spinal anesthesia. A single live male baby weighing $3.9 \mathrm{~kg}$ was delivered by cephalic presentation. Interestingly, a retro-placental submucous myoma was found intra-operatively in the right fundal area measuring $5 \mathrm{~cm} * 5 \mathrm{~cm}$. There was no intra-operative or post-operative complication. Patient got discharged on the 5th postoperative day with routine post-operative advice. CONCLUSION: Sub-mucous myomas prevent implantation and growth of the embryo and thereby cause infertility in most of the cases. Chance of progressing to term pregnancy with successful outcome is very rare. This type of cases should be managed with expertise obstetric guidance and care.
\end{abstract}

KEYWORDS: Sub-mucous myoma, Pregnancy, Infertility.

INTRODUCTION: Myomas are the most common benign tumors of the female genital tract and are associated with numerous clinical problems including a negative impact on fertility. Myomas that compress the uterine cavity like submucous myomas significantly reduce pregnancy rates. Here we present a very rare case of successful pregnancy with submucous myoma without any intra-partum or post-partum complication, in the department of Obstetrics and Gynecology of our institution, Regional Institute of Medical Sciences, Imphal, Manipur, India.

CASE REPORT: A 29 year old primi- gravida (G1 P0+0+0+0) woman with term pregnancy (39 weeks 2days) came to the out-patient department, of the department of Obstetrics and Gynecology with pain abdomen on 26th July, 2013 and got admitted in the antenatal ward. She was married for 1 year. Her menstrual history was normal. There was neither any significant past medical or surgical history of illness nor any significant family history. Her general condition was fair. Systemic examination was normal.

On per abdominal examination, her uterus was term size, irritable, baby seemed to be little big with cephalic presentation and the head was not engaged. Fetal heart sound was normal. On per vaginal examination cephalo- pelvic disproportion was detected with cervical os $3 \mathrm{~cm}$ dilated, cervix $50 \%$ effaced, membrane + and station high up. Her Complete blood count, liver and kidney function tests, routine urine examinations, random blood sugar were all within normal limit. The patient was taken up for emergency lower segment caesarean section under spinal anesthesia. 


\section{CASE REPORT}

A single live male baby of $3.9 \mathrm{~kg}$ was delivered by cephalic presentation. Interestingly, a retroplacental submucous myoma was found intra-operatively in the right fundal area measuring $5 \mathrm{~cm} * 5$ $\mathrm{cm}$ with evidence of retro placental hemorrhage. There was no intra-operative or post-operative complication. Patient got discharged on the 5 th post-operative day with routine post-operative advice.
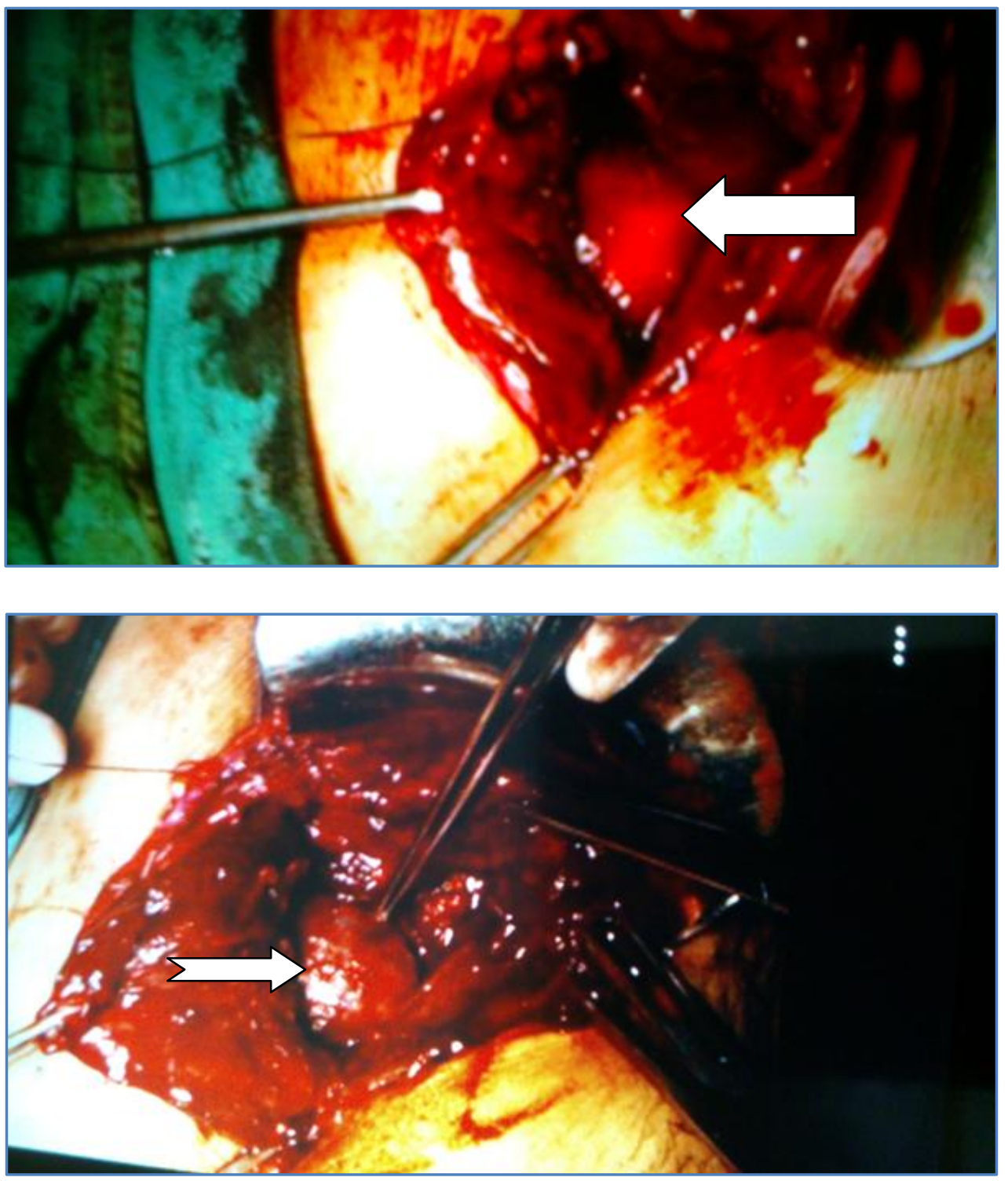

DISCUSSIONS: Fibroids are common benign tumors of uterine origin that may develop as variably sized solitary tumors or as aggregated clusters. Their growth appears to be hormone (estradiol, progesterone) dependent. They may grow towards the uterine cavity (submucous) or towards the abdominal cavity (subserosal), or they may be located within the uterine wall (intramural). Fibroids may be asymptomatic or could be associated with a variety of complaints. Symptoms, such as menometrorrhagia, pressure symptom, urinary frequency, constipation, and pain, are associated with size, number, and location of the fibroids. 
Submucosal fibroids cause a mechanical distortion of the endometrial cavity and alter gamete and embryo transport (due to blockage of the tubal ostia or by altering uterine contractility and peristalsis) and prevent subsequent embryo implantation. They cause disruption of the junctional zone within the myometrial layer, affecting the initial stages of embryo invasion and later placentation.

Altered vasculature due to the abnormal expression of angiogenic factors by uterine fibroids (such as basic fibroblast growth factor and platelet-derived growth factor) plays a role in a reduced implantation rate. Changes in the endometrium mediated by inflammation and factors involved in the process of fibrosis (such as transforming growth factor) also have a detrimental effect.

Fibroids affect gene expression pattern in the endometrium (such as HOXA10), disrupting the window of implantation. ${ }^{1}$

Study shows that the uterine cavities of women with submucous fibroids produce decreasing amount of substances favourable to early pregnancy development like glycodelin and IL-10 in midluteal phase. ${ }^{2}$

Fibroids increase the risk of several obstetric complications, including miscarriage, caesarean delivery, malpresentation, postpartum haemorrhage, retained placenta, intrauterine growth retardation, preterm labour, placenta previa, and abruption. ${ }^{3}$

European Society of Gynaecological Endoscopy (ESGE) classification of submucous myomas ${ }^{4}$

Type 0 -Entirely within endometrial cavity (pedunculated)

Type I $<50 \%$ myometrial extension (sessile)

Type II $>50 \%$ myometrial extension (sessile)

The most common treatment for submucous myoma with infertility is transcervical resectoscopic myomectomy (TCRM). Fertility rates increased after TCRM for type 0 and type 1 myomas but for type 2 myomectomy should be accomplished by a transabdominal route. ${ }^{5}$

CONCLUSIONS: Sub mucous myoma is associated with lots of complications \& adverse effects on pregnancy. On a very rare occasion, even if the conception occurs, chances of pain, malpresentation of the foetus, need for caesarean delivery, intra or post-partum haemorrhage, and inversion of the uterus are much common in pregnancy with sub-mucous myoma. Chance of progressing to term pregnancy with successful outcome is very rare. This type of cases should be managed with expertise obstetric guidance and care.

\section{REFERENCES:}

1. Horne AW, Critchley HO. The effect of uterine fibroids on embryo implantation. Semin Reprod Med. 2007 Nov; 25 (6): 483-9.

2. Ben-Nagi J, Miell J, Mavrelos D, Naftalin J, Lee C, Jurkovic D. Endometrial implantation factors in women with submucous uterine fibroids. Reprod Biomed Online. 2010Nov; 21 (5): 6105.doi:10.1016/j.rbmo.2010.06.039. Epub 2010 Sep 28.

3. Olive DL, Pritts EA. Fibroids and reproduction. Semin Reprod Med. 2010 May; 28 (3): 218-27.

4. Wamsteker K, Emanuel MH, de Kruif JH. Transcervical hysteroscopic resection of submucous fibroids for abnormal uterine bleeding: results regarding the degree of intramural extension. Obstet Gynecol. 1993; 82: 736-740. 


\section{CASE REPORT}

5. Olive DL. The surgical treatment of fibroids for infertility. Semin Reprod Med. 2011 Mar; 29 (2): 113-23.

\section{AUTHORS:}

1. Susmita Bhattacharya

2. Harish K. M.

3. Nonibala Devi

4. N. Nabakishore Singh

5. L. Ranjit Singh

\section{PARTICULARS OF CONTRIBUTORS:}

1. Post Graduate Trainee, Department of Obstetrics and Gynaecology, Regional Institute of Medical Sciences, Imphal, Manipur, India.

2. Senior Resident, Department of Obstetrics and Gynaecology, Regional Institute of Medical Sciences, Imphal, Manipur, India.

3. Associate Professor, Department of Obstetrics and Gynaecology, Regional Institute of Medical Sciences, Imphal, Manipur, India.

4. Professor, Department of Obstetrics and Gynaecology, Regional Institute of Medical Sciences, Imphal, Manipur, India.
5. Professor, Department of Obstetrics and Gynaecology, Regional Institute of Medical Sciences, Imphal, Manipur, India.

\section{NAME ADDRESS EMAIL ID OF THE CORRESPONDING AUTHOR:}

Dr. Susmita Bhattacharya, Post Graduate Trainee, Department of Obstetrics and Gynaecology, Regional Institute of Medical Sciences, Imphal-795004, Manipur, India.

Email: susmitabhattacharya25@gmail.com

Date of Submission: 18/06/2014. Date of Peer Review: 19/06/2014. Date of Acceptance: 01/07/2014. Date of Publishing: 08/07/2014. 